\title{
Global Trigger Tool: Proficient Adverse Drug Reaction Autodetection Method in Critical Care Patient Units
}

\author{
Amee D Pandya ${ }^{1}$, Kalan Patel ${ }^{2}$, Devang Rana ${ }^{3}$, Sapna D Gupta ${ }^{4}$, Supriya D Malhotra ${ }^{5}$, Pankaj Patel ${ }^{6}$
}

\begin{abstract}
Background: Emergency department (ED) being the most crucial part of hospital, where adverse drug reactions (ADRs) often go undetected. Trigger tools are proficient ADR detection methods, which have only been applied for retrospective surveillance. We did a prospective analysis to further refine the trigger tool application in healthcare settings.

Objective: To estimate the prevalence of ADRs and prospectively evaluate the importance of using trigger tools for their detection.

Materials and methods: A prospective study was conducted in the ED for the presence of triggers in patient records to monitor and report ADRs by applying the Institute for Healthcare Improvement (IHI) trigger tool methodology.

Results: Four hundred sixty-three medical records were analyzed randomly using 51 trigger tools, where triggers were found in 181 (39.09\%) and ADRs in 62 (13.39\%) patients. The prevalence of ADR was 13.39\%. According to the World Health Organization (WHO)-Uppsala Monitoring Centre (UMC) causality scale, $47(75.8 \%)$ were classified as probable and $15(24.2 \%)$ as possible, wherein $39(62.9 \%)$ were predictable and 8 (12.9\%) were definitely preventable. Most common triggers were abrupt medication stoppage (34.98\%), antiemetic use (25.91\%), and time in ED $>6$ hours (17.49\%). The positive predictive values (PPVs) of triggers such as international normalized ratio (INR) $>4(p=0.0384)$, vitamin $\mathrm{K}$ administration ( $p=0.002)$, steroid use $(p=0.0001)$, abrupt medication stoppage $(p=0.0077)$, transfusion of blood or blood products $(p=0.004)$, and rash $(p=0.0042)$ showed statistically significant results, which make the event detection process more structured when these triggers are positive. Presence of five or more triggers has statistically significant chances of developing an ADR $(p<0.05)$.

Conclusion: Trigger tool could be a viable method to identify ADRs when compared to the traditional ADR identification methods, but there is insufficient data on IHI tool and its use to identify ADRs in the general outpatient setting. Healthcare providers may benefit from better trigger tools to help them detect ADRs.
\end{abstract}

Keywords: Adverse drug reactions, Emergency department, Pharmacovigilance, Trigger tool.

Indian Journal of Critical Care Medicine (2020): 10.5005/jp-journals-10071-23367

\section{INTRODUCTION}

The emergency department (ED) is the most crucial and confluencing part of a hospital, where clinicians often miss out adverse drug reactions (ADRs). In such a setting, the use of trigger tools escorts the clinicians to identify, determine, treat, and prevent ADRs.

The World Health Organization (WHO) Collaborating Centers for International Drug Monitoring defines an ADR as follows: "Noxious and unintended and occurs at doses used in man for prophylaxis, diagnosis, therapy, or modification of physiologic functions." ${ }^{11}$

Traditional efforts to detect adverse reaction have focused on voluntary reporting and tracking of errors. However, public health researchers have established that only $10-20 \%$ of errors is ever reported, and of those, $90-95 \%$ causes no harm to patients. ${ }^{2}$ Hospitals need a more effective way to identify events that do cause harm to patients in order to quantify the degree and severity of harm and to select and test changes to reduce harm.

The term "trigger tool" was first coined in the USA in the early 1990s to describe a method used to detect potential adverse drug events. The US Institute for Healthcare Improvement (IHI) refined this process and developed the global trigger tool to quantify adverse events more generally using a simple and replicable process. ${ }^{3-5}$ The institutions can apply these methods to randomly select medical records every month in order to track their ADR records and rate over time. Majority of the studies imply on the retrospective use of these methods, but retrospective record review relies primarily on what providers document in the clinical record. ${ }^{6}$

\begin{abstract}
${ }^{1-3,5}$ Department of Pharmacology, Smt. NHL Municipal Medical College, Ahmedabad, Gujarat, India

${ }^{4}$ Department of Emergency Medicine, Smt. NHL Medical College, Ahmedabad, Gujarat, India

${ }^{6}$ Department of Orthopedics, Smt. NHL Municipal Medical College, Ahmedabad, Gujarat, India
\end{abstract}

Corresponding Author: Devang Rana, Department of Pharmacology, Smt. NHL Municipal Medical College, Ahmedabad, Gujarat, India, Phone: +91 9426418842, e-mail: devangrana@hotmail.com

How to cite this article: Pandya AD, Patel K, Rana D, Gupta SD, Malhotra SD, Patel P. Global Trigger Tool: Proficient Adverse Drug Reaction Autodetection Method in Critical Care Patient Units. Indian J Crit Care Med 2020;24(3):172-178.

Source of support: Nil

Conflict of interest: None

To overcome these limitations, we supplemented that a prospective surveillance method would foster rich characterization and identification of factors contributing to ADRs in real time, thus helping in quality improvement initiatives. By concentrating on the events actually experienced by patients, a hospital can begin to foster a culture of safety that shifts from individual blame for errors to comprehensive system redesign that reduces patient suffering.

Our setup being an ADR monitoring center (AMC) under Pharmacovigilance Program of India, no such study has been under taken as yet in our setup as well as at the national level. 


\section{Materials and Methods}

We scrutinized a prospective observational study on one 60-bed emergency medicine department, which records 2,000 indoor cases and 12,000 outdoor cases yearly, in our tertiary care academic medical hospital. The study protocol was approved by the institutional review board. The study gathered data from 463 randomly selected patients admitted in the ED between August 2018 and May 2019 after taking written informed consent. We used random selection method as it increases the chance that the characteristics of the sample will be representative of the characteristics of the population. Data were entered in the standard case record form. Global trigger tools ${ }^{7}$ were utilized for the detecting, monitoring, reporting, and analyzing ADRs of all the patients admitted in the emergency medicine ward (Flowchart 1).

Inclusion criteria are all patients should be above 18 years of age admitted to emergency medicine department, after random selection. Patients who were less than 18 years, patients not willing to give their informed consent, and patients treated on outpatient department basis were excluded from the study. After prospective data collection, we excluded patients if their medical record could not be located or if data on inclusion and exclusion criteria were missing. We focused on emergency medicine ward as it is the department most likely and more prone to ADRs because of the nature of patients and the care they receive. Three clinical pharmacologists collected demographic and clinical information from patients at the point of care and reviewed the medical records in the ED. The charts were reviewed by the clinical pharmacologist for 20 minutes and triggers were identified in the records. The sections of records reviewed in order were medications administration records, laboratory results, prescription orders, operative record (operative report and anesthesia record, if applicable), nursing notes, physician progress notes, and discharge summary (if applicable). The pharmacologist also evaluated whether the patient's visit was due to an ADR or did the ADR occur after their admission. Also the patients were interrogated if they had experienced any ADRs during their hospital stay. The physician was also consulted whether he/she believed the patient had suffered an ADR, so that the investigators do not miss the ADRs not captured in clinical notes. All admitted patients who gave their consent were followed until hospital discharge, irrespective of their presence of ADR. Whenever any trigger was found, the records were investigated in-depth to determine the occurrence of an ADR. Occasionally ADRs with no antecedent trigger are also reported. Triggers were based on the study by the $\mathrm{IHI}^{7}$ which developed a list of global triggers that can

Flowchart 1: Evaluation of patient profiles in emergency department

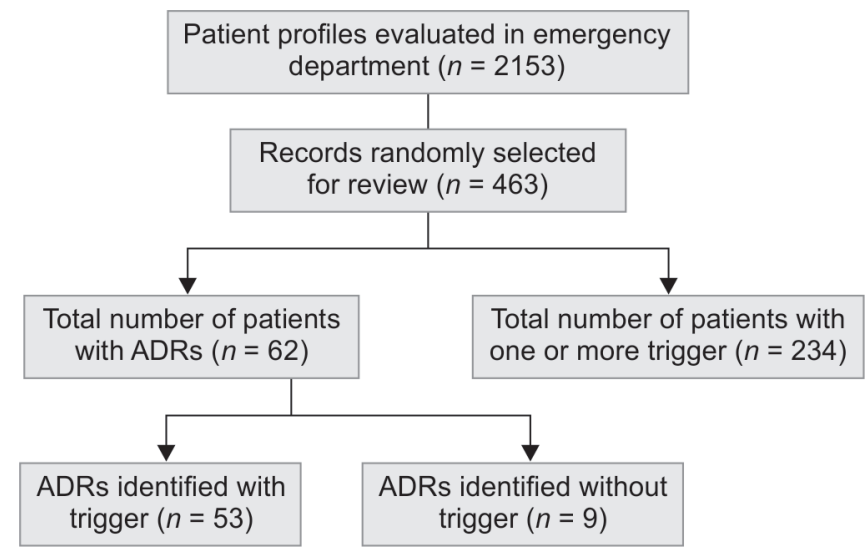

measure adverse events and be used in any health service. They were not specific for ED, but their applicability was analyzed in this study. Suspected ADRs were notified and documented in the ADR form [Pharmacovigilance Program of India-National Coordinating Council (PvPI-NCC Indian Pharmacopoeia Commission (IPC))]. Data collected were analyzed for parameters such as age-group and gender distribution, spectrum of ADRs, suspected drug, and drug class. Number of days between drug exposure and development of ADR was also reported.

Type of ADR was analyzed according to Rawlins and Thompson classification. ${ }^{8}$ Causality assessment of the ADRs was done using WHO-UMC Criteria. ${ }^{9}$ Severity and preventability were analyzed according to the Modified Hartwig and Seigel scale ${ }^{10}$ and Modified Schumock and Thornton scale, ${ }^{11}$ respectively. Harm categorization was assessed for the observed ADRs using NCC for Medication Error Reporting and Prevention Index (NCC MERP). The data collected was also uploaded to the WHO Uppsala Monitoring Centre via VIGIFLOW under the Pharmacovigilance Program of India (PvPI) by the AMC at our institute.

\section{Statistical Analysis}

The analysis was performed using SPSS statistics version 25 . Descriptive statistics was used to summarize the baseline characteristics of the patient population. We estimated the sensitivity of the trigger tools by dividing the number of records with one or more ADRs identified using the trigger tool by the total number of records, with ADRs identified during the prospective study, multiplied by 100 . We estimated the specificity of the trigger tools by dividing the number of records that screened negative using the trigger tool without ADRs by the total number of charts without ADRs, multiplied by 100. Comparisons between groups were made by using the Chi-square test for categorical variables and $t$ test for continuous variables. Logistic regression was used to investigate the risk factors associated with ADRs. The $p$ values $<$ 0.05 were considered statistically significant.

\section{Results}

\section{Population Characteristics}

A total of 2,153 patients were admitted in the ED during the study period from August 2018 to May 2019. We randomly assessed records of 463 patients in which triggers were present in 235 $(50.75 \%)$ of the cases. Prevalence of ADRs reported during the study was $13.39 \%$ ( $n=62)$; of which, 53 (85.48\%) ADRs were found by triggers and 9 (14.51\%) ADRs were found spontaneously without the presence of a trigger. The fatal ADR incidence was $0.6 \%$. Among the 62 patients with ADR, 16 (25.8\%) patients had an ADR on admission, whereas 46 (74.1\%) developed ADR while admitted in the emergency room (ER). The mean age of patients from the ED randomly selected for review $(n=463)$ was $47 \pm 14$ years. Male $(285$, $61.5 \%)$ preponderance was observed over females (178, 38.44\%). Of all hospital admissions, $7.5 \%$ were caused by ADRs, as $43.54 \%$ of the hospitalized patient's experience an ADR during their hospital stay. No statistically significant differences were observed in age, gender, and length of stay $(p>0.05)$, as shown in Table 1.

\section{Evaluation of ADRs at the Point of Care}

The trigger tool identified 53 (85.48\%) ADRs, the most frequent was cutaneous reactions (detected by triggers "rash," "pruritus," "steroid," and "antihistamine use") followed by bleeding episodes (detected by the triggers "abrupt hemoglobin reduction $>4 \mathrm{~g} / \mathrm{dL}$," 
Table 1: Demographic characteristics of the patients admitted to emergency medicine unit of a tertiary care teaching hospital, India

\begin{tabular}{ll}
\hline Variables & $p$ value \\
\hline Gender, $n(\%)$ & $0.2829^{\mathrm{a}}$ \\
Male, $285(61.5 \%)$ & \\
Female, $178(38.44 \%)$ & \\
Length of stay $(9.3 \pm 5.28$ days) & $0.3082^{\mathrm{a}}$ \\
Mean age (47 \pm 14 years) & $0.2451^{\mathrm{a}}$ \\
\hline
\end{tabular}

anpaired $t$ test

"vitamin K administration," "INR $>4$ and partial thromboplastin time $>100$ seconds") and hypoglycemia (screened by "glucose lower than $<50 \mathrm{mg} / \mathrm{dL}^{\prime}$ ). Eight ADRs were identified spontaneously without any trigger, which included sialorrhea, dry cough, constipation, drug-withdrawal seizures, and bradycardia. Table 2 refers to different ADRs detected during the study period, while Figure 1 shows the most common systems presenting ADRs.

The most common drugs causing ADRs were anti-infectives (51.6\%), anticoagulants (19.35\%), antihypertensives (16.12\%), and nonsteroidal anti-inflammatory drugs (NSAIDs) (8.06\%). These findings were similar to the data reported by Joshua et al. ${ }^{12}$ who verified the greater frequency of events related to the use of antimicrobials and cardiovascular agents. It was found that $12.9 \%$ of the ADRs were definitely preventable (Fig. 2), which included drug overdose toxicity, NSAID-induced analgesic nephropathy, clonidine withdrawal hypertension, and drug withdrawal seizures, whereas 31 (50\%) ADRs were not preventable with 21\% ADRs reported as severe as shown in Figure 3.

Majority (62.9\%) of the ADRs were predictable. In our study, these included intraparenchymal hemorrhage and bleeding induced by anticoagulants, calcium channel blocker-induced pedal edema, antibiotic-associated diarrhea, clonidine-withdrawal hypertension and drug-withdrawal seizures, dry cough by enalapril, and hypoglycemia with insulin and oral hypoglycemics. Skin rash and hypersensitivity with antibiotics and antiepileptics were among the unpredictable ADRs (30.6\%) and weight gain with antidepressants, NSAID-induced acute on chronic renal failure, and increased incidence of pathological fracture with steroids were among the chronic ADRs (6.4\%), respectively (Fig. 4).

Stratifying by age, $69.54 \%$ were between 18 years and 59 years, and $18.57 \%$ were 60 years or older. Applying the WHO-UMC causality scale to evaluate the causality of an ADR, we found that 15 (24.2\%) were classified as possible and $47(75.8 \%)$ as probable ADRs. No reaction cases were classified as doubtful or definite (Fig. 5).

Of the 62 ADRs observed in the sample, $22.6 \%$ required hospitalizations that lasted from 2 days to 20 days (Fig. 6). Cardiovascular ADRs detected by trigger tool method were more likely to detect episodes of hypotension within the cardiac complications ( $p=0.0025$ ). The early identification of this event can prevent complications such as kidney failure and ischemic events and can allow the development of strategies to minimize healthcare-related risks.

\section{Evaluation of Trigger Tools}

Most common triggers flagged in our study were abrupt medication stoppage (34.98\%), antiemetic use (25.91\%), time in ED $>6$ hours (17.49\%), and abnormal blood urea creatinine (10.79\%). The sensitivity of the trigger tools for records containing one or more ADRs was $85.48 \%$ (95\% Cl $74.22,93.14 \%)$, while the specificity
Table 2: Classification of adverse drug reactions as to the affected organic system, according to the Common Terminology Criteria for Adverse Events (CTCAE v5.0) with suspected drugs detected in an emergency medicine unit in our study

\begin{tabular}{|c|c|}
\hline Organic system adverse drug event (suspected drug) & $n(\%)$ \\
\hline Metabolism and nutritional disorders & $5(8.06)$ \\
\hline Hypoglycemia (insulin, metformin, glipizide) & 3 \\
\hline $\begin{array}{l}\text { Hypokalemia (piperacillin-tazobactam, mannitol, } \\
\text { sertraline, caspofungin) }\end{array}$ & 4 \\
\hline Hyperkalemia (spironolactone) & 1 \\
\hline Hyponatremia (hydrochlorothiazide) & 1 \\
\hline Hypernatremia (mannitol, hypertonic saline, lithium) & 3 \\
\hline Blood and lymphatic system disorders & $10(16.1)$ \\
\hline \multicolumn{2}{|l|}{$\begin{array}{l}\text { Bleeding (warfarin, enoxaparin, streptokinase, } \\
\text { tenecteplase, NSAIDs) }\end{array}$} \\
\hline Gastrointestinal disorders & $13(21)$ \\
\hline $\begin{array}{l}\text { Diarrhea (amoxycillin-clavulanic acid, cefixime, } \\
\text { nutritional supplements, clindamycin, ceftriaxone) }\end{array}$ & 9 \\
\hline Constipation (ranitidine, olanzapine) & 3 \\
\hline Vomiting (oseltamivir) & 1 \\
\hline Cardiac disorders & $12(19.3)$ \\
\hline $\begin{array}{l}\text { Hypotension (chlordiazepoxide, amlodipine, furo- } \\
\text { semide, hydralazine, chlorpromazine) }\end{array}$ & 11 \\
\hline Hypertension (clonidine withdrawal) & 1 \\
\hline Bradycardia (metoprolol, propranolol) & 2 \\
\hline Skin and subcutaneous tissue disorders & $11(17.7)$ \\
\hline Rash acneiform (prednisolone) & 1 \\
\hline $\begin{array}{l}\text { Rash maculopapular (amoxycillin-clavulanic acid, } \\
\text { levofloxacin, cefixime, sulfonamides) }\end{array}$ & 5 \\
\hline Steven-Johnsons syndrome (phenytoin) & 2 \\
\hline Toxic epidermal necrolysis (phenytoin, paracetamol) & 2 \\
\hline Urticaria (amoxycillin-clavulanic acid, vancomycin) & 2 \\
\hline Renal and urinary disorders & $2(3.2)$ \\
\hline \multicolumn{2}{|l|}{ Acute kidney injury (NSAIDs) } \\
\hline Nervous system disorders & $5(8.06)$ \\
\hline Headache (valproate, sumatriptan, paracetamol) & 3 \\
\hline Seizure (isoniazid) & 1 \\
\hline Tremor (propranolol) & 1 \\
\hline Psychiatric disorders & $1(1.6)$ \\
\hline Suicide attempt (olanzapine) & 1 \\
\hline Investigation & $2(3.2)$ \\
\hline $\begin{array}{l}\text { Platelet count decreased (low-molecular-weight } \\
\text { heparin) }\end{array}$ & 1 \\
\hline Altered liver function (AKT) & 1 \\
\hline
\end{tabular}

evaluated was $54.86 \%(95 \% \mathrm{Cl} 49.85,59.81 \%)$. The overall PPV was $22.65 \%(95 \% \mathrm{Cl} 20.15,25.36 \%)$, while their negative predictive value was $96.07 \%$ (95\% Cl 92.99, 97.83\%). The low overall PPV can be attributed to the low prevalence of ADR in our study.

The PPVs of triggers such as INR $>4(p=0.0384)$, vitamin $\mathrm{K}$ administration $(p=0.002)$, steroid use $(p=0.0001)$, abrupt medication stoppage ( $p=0.0077)$, transfusion of blood or blood products $(p=0.004)$, and rash $(p=0.0042)$ showed statistically significant results which make the event detection process more structured than chart review and deserve recognition regarding their performance in identifying ADRs. Presence of five or more 


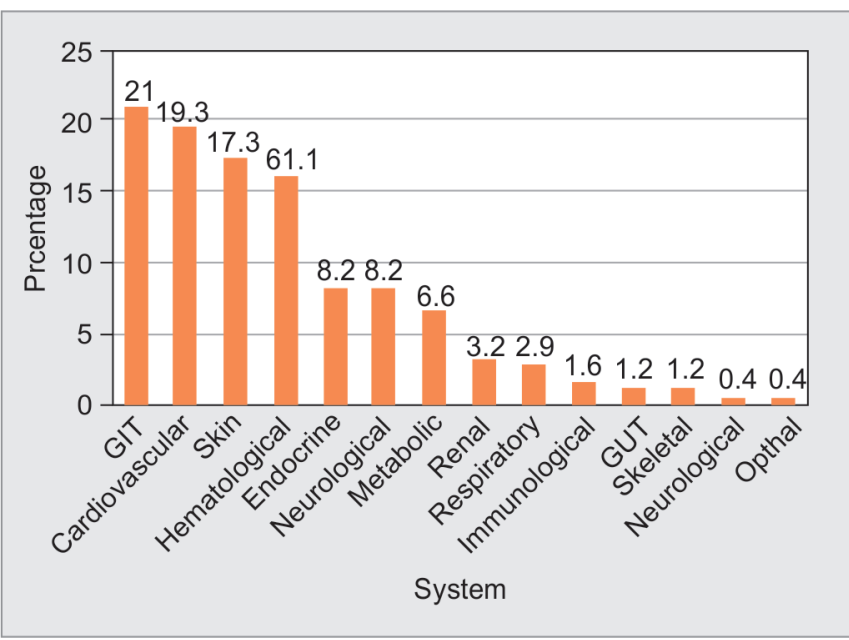

Fig. 1: Most common systems presenting with adverse drug reactions

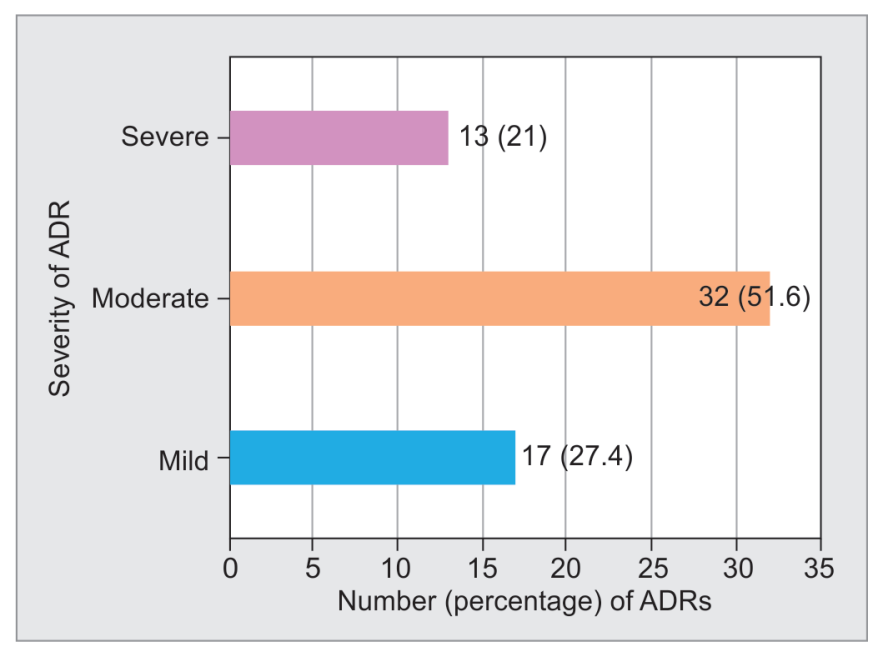

Fig. 3: Modified Hartwig and Seigel severity scale

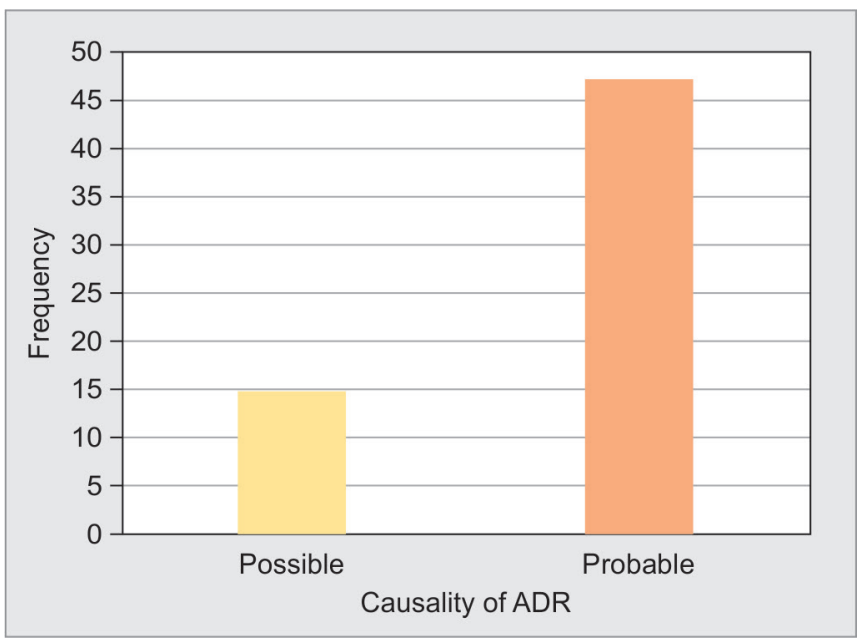

Fig. 5: World Health Organization-UMC causality criteria

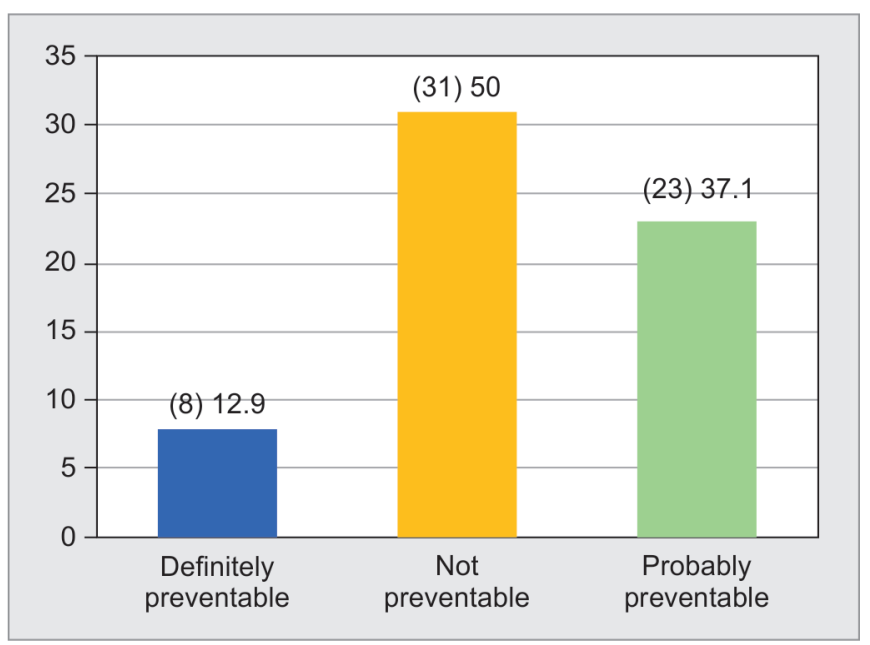

Fig. 2: Modified Schumock and Thornton adverse drug reaction preventability scale

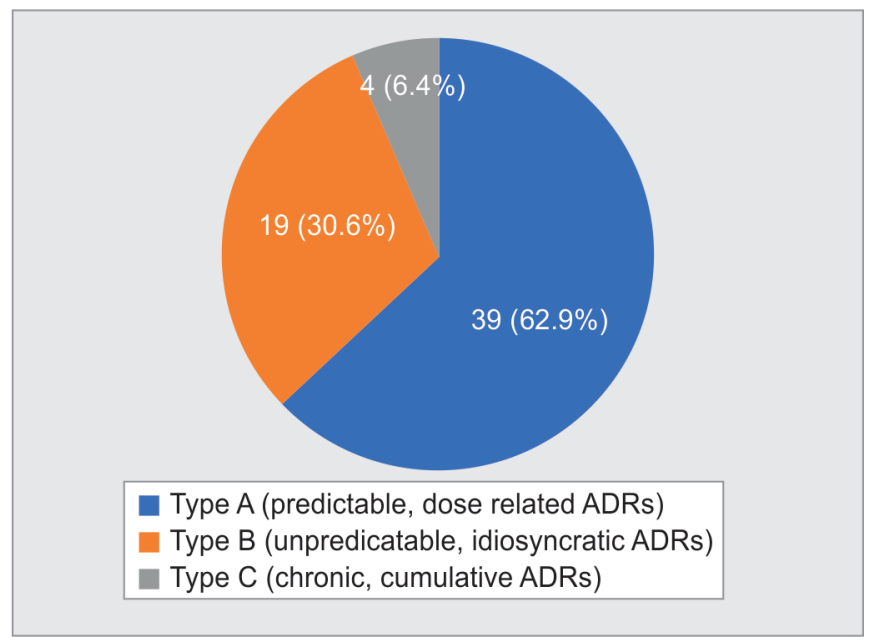

Fig. 4: Rawlins and Thompson classification

triggers in patient records have statistically significant chances of developing an ADR ( $p<0.05)$. Triggers such as antiemetic use, time in ED $>6$ hours, abnormal electrolytes, rising blood urea nitrogen or serum creatinine $>2$ times baseline, abrupt medication stop/withdrawn, and glucose $<50 \mathrm{mg} / \mathrm{dL}$ had low PPVs, though they were among the most common triggers observed (Table 3).

Records of all the randomly assessed patients, irrespective of the presence of an ADR, were reviewed retrospectively for the presence of an ADR or a trigger, which was presumptive to conclude that ADRs can be avoided with early identification using trigger tools.

\section{Discussion}

Based on prevalence studies in different settings, approximately 5 to $35 \%$ of hospital admissions are due to ADRs..$^{13-16}$ In our study, it was reported that the prevalence of ADRs was $13.39 \%(n=62)$; 


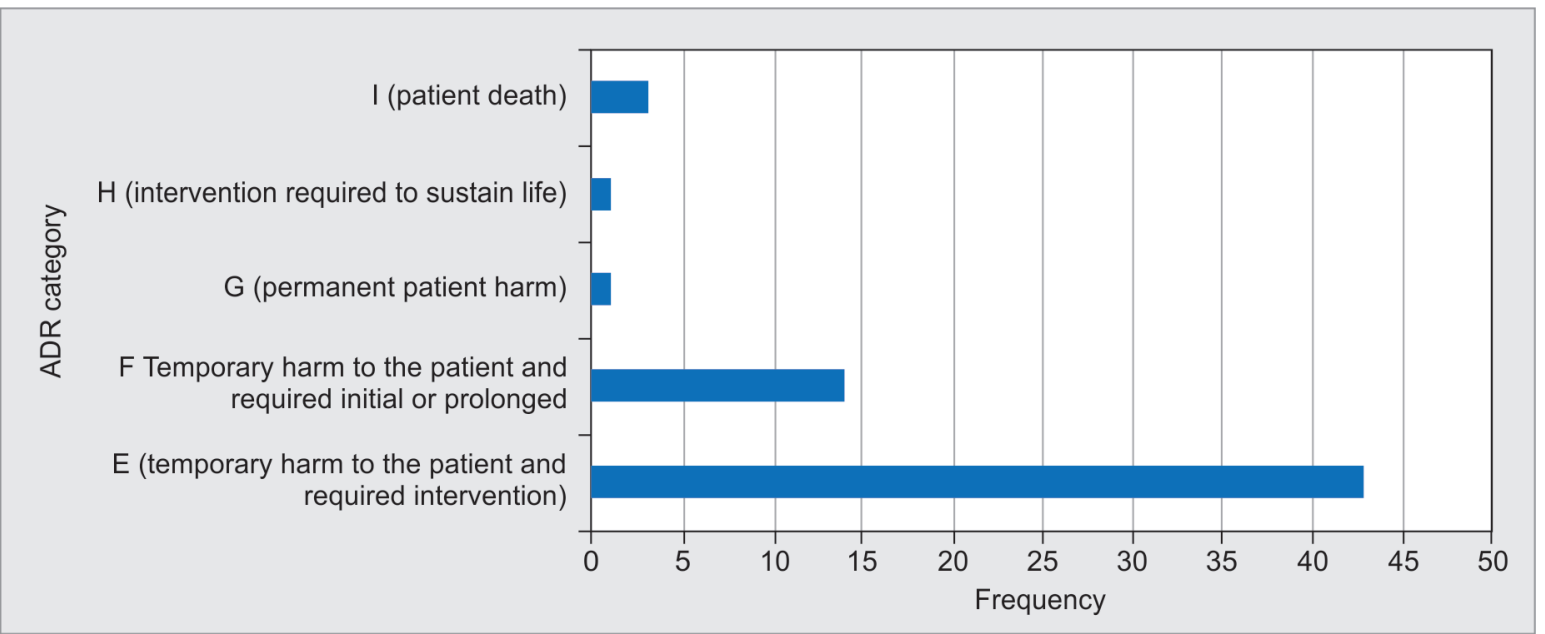

Fig. 6: National Coordinating Council Medication Error Reporting and Prevention (NCC MERP) index harm category of adverse drug reaction

of which, 53 (85.48\%) ADRs were found by triggers and 9 (14.51\%) ADRs were found spontaneously without the presence of a trigger. The actual incidence of ADRs may be even greater because some ADRs mimic natural disease states and may thus go undetected and/or unreported. The preventability assessment revealed that most of the ADEs (50.0\%) were preventable (12.9\% of the ADEs were definitely preventable, while $37.1 \%$ were probably preventable). The most common drugs causing ADRs were anti-infectives (51.6\%), anticoagulants (19.35\%), antihypertensives (16.12\%), and NSAIDs (8.06\%). The frequency of this medication groups among the events detected by the trigger tool corroborates the IHI recommendation to use trigger tool as a preferred strategy for detecting adverse events particularly related to high-alert medications. We found that $15(24.2 \%)$ were classified as possible and $47(75.8 \%)$ as probable ADRs, which were also similar to the findings in a British study in which the majority of the cases were considered probable (approximately 69\%) followed by possible (29\%). ${ }^{17}$

Despite a lack of consensus, important risk factors reported for ADRs include polypharmacy, female sex, administration of drugs with narrow therapeutic range, renal elimination of drug, age $>65$ years, and administration of anticoagulants or diuretics. ${ }^{18,19}$ In our study, no statistically significant differences were observed with regard to age, gender, and length of stay $(p>0.05)$, which was similar to the findings by De Almeida et al. ${ }^{19}$ We found that of all the patients presenting with ADRs, $22.6 \%$ required initial or prolonged hospitalization that lasted from 2 days to 20 days, while $69.4 \%$ of the patients required only temporary intervention. ${ }^{20}$ Most common diagnoses of ADRs were related to gastrointestinal (GI), cardiovascular, and skin conditions. An American study found their most frequent diagnoses associated with the adverse reaction to be skin conditions, Gl illnesses, and neurological conditions. ${ }^{21}$ The sensitivity of the trigger tools for records containing one or more ADRs was high (85.48\%), demonstrating the presence of one or more trigger when ADRs are suspected, whereas the specificity of trigger tools was $54.86 \%$. Also the results of our study state that the presence of five or more triggers in patient records has statistically significant chances of developing an $\operatorname{ADR}(p<0.05)$.

Triggers such as INR $>4$ when detected can suggest statistically significant ( $p=0.03$ ) risk of bleeding, which necessitates the importance of monitoring, to adjust the dosing, so that the level
Table 3: Distribution of triggers used in our study with positive predictive values (PPVs) of at least 30\% indicative of suspected adverse drug reactions in medical records of emergency department, India

\begin{tabular}{|c|c|c|c|}
\hline Trigger & $\begin{array}{l}\text { No. of times } \\
\text { the trigger was } \\
\text { detected }\end{array}$ & $\begin{array}{l}\text { No. of times } \\
\text { the trigger was } \\
\text { associated with } \\
\text { an } A D R\end{array}$ & $P P V(\%)$ \\
\hline Lithium $>1.5 \mathrm{mEq} / \mathrm{L}$ & 1 & 1 & 100 \\
\hline $\begin{array}{l}\text { Oversedation/ } \\
\text { hypotension }\end{array}$ & 19 & 11 & 57.89 \\
\hline $\begin{array}{l}\text { Transfusion of blood } \\
\text { or use of blood } \\
\text { products }\end{array}$ & 18 & 10 & 55.55 \\
\hline $\begin{array}{l}\text { Vitamin } \mathrm{K} \\
\text { administration }\end{array}$ & 24 & 13 & 54.16 \\
\hline Phenytoin $>20 \mu \mathrm{g} / \mathrm{mL}$ & 2 & 1 & 50 \\
\hline INR $>4 />6$ & 20 & 10 & 50 \\
\hline Rash & 26 & 13 & 50 \\
\hline Steroid use & 47 & 23 & 48.93 \\
\hline $\begin{array}{l}\text { Intubation/ } \\
\text { reintubation }\end{array}$ & 18 & 7 & 38.88 \\
\hline $\begin{array}{l}\text { (PTT) greater than } \\
100 \text { seconds }\end{array}$ & 8 & 3 & 37.5 \\
\hline Pruritis & 22 & 8 & 36.36 \\
\hline Antihistamine use & 46 & 16 & 34.78 \\
\hline $\begin{array}{l}\text { Clostridium difficile- } \\
\text { positive stool }\end{array}$ & 3 & 1 & 33.33 \\
\hline Pressure ulcers & 3 & 1 & 33.33 \\
\hline Pneumonia onset & 3 & 1 & 33.33 \\
\hline Platelet count $<50,000$ & 3 & 1 & 33.33 \\
\hline Epinephrine use & 3 & 1 & 33.33 \\
\hline $\begin{array}{l}\text { X-ray or Doppler } \\
\text { studies for emboli or } \\
\text { DVT }\end{array}$ & 3 & 1 & 33.33 \\
\hline $\begin{array}{l}\text { Abrupt medication } \\
\text { stop/withdrawn }\end{array}$ & 162 & 50 & 30.86 \\
\hline $\begin{array}{l}\text { Healthcare-associated } \\
\text { infections }\end{array}$ & 10 & 3 & 30 \\
\hline
\end{tabular}


of anticoagulant remains in the effective range. ${ }^{22}$ Prescription of vitamin $\mathrm{K}$ also is a significant flag $(p=0.002)$, as ADR likely occurred if there are laboratory reports indicating a drop in hematocrit or guaiac-positive stools. Check the progress notes for the evidence of excessive bruising, Gl bleed, hemorrhagic stroke, or large hematomas or it might be used to counteract an overdose of anticoagulants such as warfarin. ${ }^{22}$ Any transfusion of packed red blood cells or whole blood should be investigated for causation ( $p=0.004)$, including excessive bleeding (surgical or anticoagulant related) or unintentional trauma of a blood vessel. Patients receiving anticoagulants who require transfusion of fresh frozen plasma and platelets have likely experienced an ADR related to the use of anticoagulants. Steroid use $(p=0.0001)$ especially topical preparations are easily available in the pharmacy store and are sold without prescription. This has led to its irrational use and increased ADRs such as hypertension, peptic ulcer disease, ocular damage, neuropsychiatric effects, hematologic, and musculoskeletal effects. To prevent irreversible damage, these patients need close monitoring and follow-up, which has become a major concern. Subsequent monitoring is required in patients who require an extended course of glucocorticoids as it may trigger an ADR. Symptoms of and/or exposure to serious infections should also be assessed as corticosteroids are contraindicated in patients with untreated systemic infections. Concomitant use of other medications should also be assessed before initiating therapy as significant drug interactions have been noted between glucocorticoids and several drug classes.

Although our study was not of longer duration and did not have a large sample size, we did succeed in observing values of the estimates that differed with statistical significance between patients with or without ADRs. However, studies with larger samples should test the hypothesis of association. The less amount of time required to acquire information from medical records and the possibility of automated search are features for better applicability of this method, especially in suboptimal conditions for health services, such as those provided in developing countries.

The fact that, in our study, nine ADRs were not found by triggers reinforces the idea that maybe no single method can apprehend every ADR that occurs in hospitals. This challenges policy makers to test and harmonize different methods to address ADRs. Although we identified some ADEs using the trigger tool, more work is needed to further refine the trigger tool to reduce the false-positives and increase sensitivity.

\section{Conclusion}

Application of trigger tools to identify ADRs can be used to better understand the ADRs of patients treated in the ER and to direct actions related to pharmacovigilance in this sector. The use of trigger tool in identifying and reporting ADRs, when integrated with event monitoring, spontaneous reporting, charted review, and other techniques to improve trigger usefulness could enhance effectiveness for patient safety and can be an important strategy for indicating possible flaws in the process of using medications for hospitalized patients. Further scrutiny on the IHI Global Trigger Tool might contribute to improve its usefulness in clinical practice.

\section{Strengths and Limitations}

To our knowledge, our study represents the first detailed prospective study with application of trigger tools, which is presently in use to monitor and describe the public health burden of outpatient ADRs. Our findings have important implications for quality improvement initiatives in integrating different ADR detection methods, health surveillance, and research efforts that use trigger flags as a means of developing and evaluating strategies to improve clinical care.

Among the limitations experienced during this study, the fact that it was unicentric can be taken into account. Also we conducted the study in emergency medicine department. Using different wards in the same hospital can make it possible to identify the prevalence of ADRs on a larger basis. In the future, studies with higher number of patients may offer evidences of the association more significantly.

\section{ACKNoWledgment}

We gratefully acknowledge the emergency medicine department of our hospital, India.

\section{References}

1. Carnevali L, Krug B, Amant F, Van Pee D, Gérard V, de Béthune X, et al. Performance of the adverse drug event trigger tool and the global trigger tool for identifying adverse drug events: experience in a Belgian hospital. Ann Pharmacother 2013;47(11):1414-1419. DOI: 10.1177/1060028013500939.

2. de Wet C, Bowie P. The preliminary development and testing of a global trigger tool to detect error and patient harm in primarycare records. Postgrad Med J 2009;85(1002):176-180. DOI: 10.1136/ pgmj.2008.075788.

3. Gómez IV, Jiménez CMJ, Daniel A, Piquero FJM. Global trigger tools for the detection of adverse drug events. Eur J Clin Pharm 2016;18(1):5.

4. Sharek PJ. The emergence of the trigger tool as the premier measurement strategy for patient safety. AHRQ WebM\&M 2012;2012(5):120.

5. Pierdevara L, Margarida IV, Maria AB, Silva CS. An experience with the global trigger tool for the study of adverse events in a medical ward. NJR 2016;9(4):97-105. DOI: 10.12707/RIV15078.

6. Brenner S, Detz A, López A, Horton C, Sarkar U. Signal and noise: applying a laboratory trigger tool to identify adverse drug events among primary care patients. BMJ Qual Saf 2012;21(8):670-675. DOI: 10.1136/bmjqs-2011-000643.

7. Griffin FA, Resar RK. IHI Global Trigger Tool for Measuring Adverse Events. Cambrige: Institute for Healthcare Improvement; 2009.

8. Rawlins MD, Thompson JW. Pathogenesis of adverse drug reactions. In: Davies DM, ed. Textbook of adverse drug reactions. Oxford: Oxford University Press; 1977. p. 10.

9. The use of the WHO-UMC system for standardised case causality assessment. Accessed from: http://www.WHO-UMC.org/ graphics/4409.pdf, last accessed on 2019 April 26.

10. Hartwig SC, Siegel J, Schneider PJ. Preventability and severity assessment in reporting adverse drug reactions. Am J Hosp Pharm 1992;49(9):2229-2232. DOI: 10.1093/ajhp/49.9.2229.

11. Schumock GT, Thornton JP. Focusing on the preventability of adverse drug reactions. Hosp Pharm 1992;27(6):538.

12. Joshua $L$, Devi $P$, Guido $S$. Adverse drug reactions in medical intensive care unit of a tertiary care hospital. Pharmacoepidemiol Drug Saf 2009;18(7):639-645. DOI: 10.1002/pds.1761.

13. Beijer HJ, de Blaey CJ. Hospitalisations caused by adverse drug reactions (ADR): a meta-analysis of observational studies. Pharm World Sci 2002;24(2):46-54. DOI: 10.1023/A:1015570104121.

14. Einarson TR. Drug-related hospital admissions. Ann Pharmacother 1993;27(7-8):832-840. DOI: 10.1177/106002809302700702.

15. Kongkaew C, Noyce PR, Ashcroft DM. Hospital admissions associated with adverse drug reactions: a systematic review of prospective observational studies. Ann Pharmacother 2008;42(7):1017-1025. DOI: 10.1345/aph.1L037. 
16. Lazarou J, Pomeranz BH, Corey PN. Incidence of adverse drug reactions in hospitalized patients: a meta-analysis of prospective studies. JAMA 1998;279(15):1200-1205. DOI: 10.1001/jama.279.15.1200.

17. Pirmohamed M, James S, Meakin S, Green C, Scott AK, Walley TJ, et al. Adverse drug reactions as cause of admission to hospital: prospective analysis of 18820 patients. BMJ 2004;329(7456):15-19. DOI: 10.1136/ bmj.329.7456.15.

18. Krähenbühl-Melcher $A$, Schlienger R, Lampert $M$, Haschke $M$, Drewe J, Krähenbühl S. Drug-related problems in hospitals: a review of the recent literature. Drug Saf 2007;30(5):379-407. DOI: 10.2165/00002018-200730050-00003.

19. De Almeida SM, Romualdo A, de Abreu Ferraresi A, Zelezoglo GR, Marra AR, Edmond MB. Use of a trigger tool to detect adverse drug reactions in an emergency department. BMC Pharmacol Toxicol
2017;18(1):71. DOI: 10.1186/s40360-017-0177-y Kongkaew C, Noyce PR, Ashcroft DM. Hospital admissions associated with adverse drug reactions: a systematic review of prospective observational studies. Ann Pharmacother 2008;42(7):1017-1025. DOI: 10.1345/aph. 1 L037.

20. Prince BS, Goetz CM, Rihn TL, Olsky M. Drug-related emergency department visits and hospital admissions. Am J Hosp Pharm 1992;49(7):1696-1700. DOI: 10.1093/ajhp/49.7.1696.

21. Riley RS, Rowe D, Fisher LM. Clinical utilization of the international normalized ratio (INR). J Clin Lab Anal 2000;14(3):101-114. DOI: 10.1002/(SICI)1098-2825(2000)14:3<101::AID-JCLA4>3.0.CO;2-A.

22. Hill MR, Szefler SJ, Ball BD, Bartoszek M, Brenner AM. Monitoring glucocorticoid therapy: a pharmacokinetic approach. Clin Pharmacol Ther 1990;48(4):390-398. DOI: 10.1038/clpt.1990.167. 